With better trained family planners and improved designs of I.U.C.D.s the incidence of extrauterine devices is now much less than this. But though the complication is uncommon it will continue to give rise to some anxiety in individual patients.

1 Howard, G., Lancet, $1972,2,1339$. 2 Peel, J., and Potts, M., Contraceptive Practice. London, Cambridge

3 Mills, W., Lancet, 1965, 2, 485.

4 Year Book of Obstetrics and Gynecology, ed. J. P. Greenhill. Chicago, Year Book Medical Publishers, 1971.

5 Thambu, J., British Medical fournal, 1965, 2, 407.

6 Allen, J. R., Shemwell, R. E., Macleod, D. P., and Weed, J. C., Obstetrics and Gynecology, 1972, 40, 225.

; Ratnam, S. S., and Yin, J. C. K., British Medical fournal, 1968, 1, 612.

\section{Synergistic Bacterial Gangrene}

The synergistic bacterial gangrene described by $F$. L. Meleney ${ }^{1}$ is fortunately rare, but the relentlessly destructive progress of the missed or inadequately treated condition should ensure that it is never forgotten. Typically, it begins at the site of a drain or near retention sutures one or two weeks after lower abdominal operations, but occasionally it follows incision of the chest or other areas. The wound fails to heal; surrounding skin edges become red and later raised; and as the lesion extends circumferentially the centre becomes black and necrotic, with a surrounding zone of tender, purple, oedematous tissue beyond which there is a characteristic peripheral area of bright erythematous skin.

Bacteriological cultures made from the central slough may show only coliform organisms, but the typical synergistic pathogens, micro-aerophilic streptococci and Staphylococcus aureus, can be isolated from the advancing edges of the ulcer. Meleney was unable to reproduce the lesion experimentally unless both synergistic partners were inoculated together into the skin of rabbits and guinea-pigs. Traditionally the treatment of synergistic gangrene includes very wide excision of the whole area-conservative débridement being insufficient-together with local treatment with gauze soaked in zinc peroxide or in more recent practice, in a neomycinbacitracin mixture. $R$. W. Grainger and colleagues ${ }^{2}$ attempted to treat one of their three cases with diathermy excision of the lesion, but progressive destruction of the tissues recurred, and this patient died. Two other patients recovered after massive antibiotic therapy without radical surgical excision but with five one-hour sessions in a hyperbaric oxygen chamber. The authors believe that the rapid zessation of the progressive disease was unlikely to have been due to the antibiotic alone, but clearly the place of hyperbaric oxygen in this condition requires further investigation.

Synergistic bacterial gangrene causes the patient intense local pain, but in the early stages it progresses insidiously and there is not much evidence of toxicity.

W. J. Rea and W. J. Wyrick ${ }^{3}$ point out that necrotizing fasciitis can readily be confused with Meleney's gangrene, but it is a much more acute and highly toxic infection which causes widespread necrosis and undermining of the surrounding tissues. The main distinguishing feature is the extensive necrosis of the superficial fascia. Of the 44 cases of fasciitis investigated in one hospital by Rea and Wyrick over a period of 15 years 35 became infected after an initial injury outside hospital, while in nine the infection followed surgical operation. Many of the injuries were trivial and included abrasions, bruises, and insect bites. There were 13 deaths in the series, including five of eight patients with diabetes, and nearly all the deaths were in the elderly. From most of these cases two potentially pathogenic species of organism were recovered, most frequently $\beta$-haemolytic streptococci and Staphylococcus aureus, but in other cases only coliform organisms were isolated from a serosanguineous exudate or from the dull grey and necrotic fascia. All were treated with massive doses of parenteral as well as local antibiotics administered by drip into the wounds, which were loosely packed with fine mesh gauze.

Six cases recently described by D. B. Roberts and L. L. Hester $^{4}$ as examples of synergistic bacterial gangrene appear to have had most of the features of necrotizing fasciitis. The patients were all adults and all had diabetes with ketoacidosis, and in each case the initial lesion was an abscess either of the ducts of Bartholin's gland or of the vulva. In all cases at least two organisms were involved and in four gas-producing bacteria were recovered. Four patients were treated with antibiotics incision, and débridement, and three of them died. The fourth survived only as a permanent invalid after surgery that eventually included excision of the soft tissues down to the bladder and removal of both rami of the symphysis pubis, necessitated by osteomylitis Two patients were treated by wide excision extending beyond the areas of tissue necrosis and induration, and both of them survived. This distressing but instructive account underlines again the need for the earliest possible recognition of relatively minor infections in elderly diabetic patients, and also, it should be added, in post-partum women, when prompt and appropriate bactericidal therapy may arrest spread before destruction of tissue makes radical and immediate surgical intervention inevitable.

1 Meleney, F. L., Annals of Surgery, 1931, 94, 961.

2 Grainger, R. W., MacKenzie, D. A., and McLachlin, A. D., Canadian Fournal of Surgery, 1967, 10, 439.

3 Rea, W. J., and Wyrick, W. J., Annals of Surgery, 1970, 172, 957.

Roherts, D. B., and Hester, L. L., American fournal of Obstetrics and Gynaecology, 1972, 114, 285.

\section{Free Contraception}

Sir Keith Joseph's proposal to include contraception within the Health Service, announced when he opened the second reading of the N.H.S. Reorganization Bill (p. 62), is a welcome change of attitude by the Government; so it may seem unreasonable to argue that the proposals are still unsatisfactory because pills and appliances will carry a precription charge. But the arguments for free contraception are not based on intellectuals' liberal theories, they are practical and important.

Experience at the local authority clinics established to provide contraception in poor social areas has been that the offer of a free service has been remarkably successful ${ }^{1}$ in attracting the parents in most need of advice-and that they have returned for follow-up visits. Much of the goodwill established by these clinics would be lost if charges had to be introduced in 1974, as they would have to be if the Government's proposal became law. Sir Keith's statement seems to imply that the supply of contraceptives by general practitioners for non-medical reasons would be limited to appliances obtainable only on prescription. Again experience 
has shown the difficulties that are created when distinctions of this kind have to be applied by the doctor during the consultation. Earlier this year $^{2}$ the G.M.S. Committee stressed that in the general practice setting it makes no sense at all to try to draw a distinction between medical and social needs for contraception.

Finally, the exclusion of contraceptives from prescription charges can be justified on the grounds that their provision is a part of preventive medicine. Patients are not charged for their immunizations, cervical smears, or routine chest $x$-rays; these procedures are encouraged as benefitting the community as well as the individual. The same argument applies to family planning. Society has as valid an interest in reducing the numbers of unwanted pregnancies as it had a century ago in securing pure water supplies.

\footnotetext{
1 Hansard, House of Commons, 26 March 1973, cols. 956, 996, and 1038.

2 British Medical fournal Supplement, 1973, 1, 13.
}

\section{Handling the Hijacker}

Many countries-probably approaching 50-have had their airlines hijacked at one time or another. The phenomenon of air piracy is not a new one. The first reported event was in 1930 during a revolution in Peru, and it was somewhat ironic that the same pilot was hijacked once again in El Paso during August 1961. In 196982 hijacks were attempted, of which 70 were successful in that the hijackers reached a desired destination or obtained a ransom. Sixty-six of these piratical attacks took place over the Americas (North America 37, Latin America plus the Caribbean countries 29). Since that year the numbers of attempts fell to 72 in 1970 and to 61 in 1971 but rose again to 64 in $1972 .{ }^{1}$ Much more notable than the decline in attempts has been the decline in the numbers of attacks that were successful. From 70 in 1969 these fell to 46 in 1970, to 24 in 1971, and to 18 in 1972. The Federal Aviation Administration of the United States made a detailed analysis of the problem during the latter years of the 1960s, and their experience has been of great value in combating the present problem.

The initial approach is to dissuade the hijacker by publicity which suggests the unlikelihood of success and the sorry fate of even successful hijackers, for they are often an embarrassment to the countries they reach. The would-be hijacker who nevertheless pursues his objective must pass the scrutiny of airline personnel trained to detect certain behavioural characteristics. Experience has shown that hijackers are sufficiently different from the usual airline population to provide behavioural criteria which allow about $99.5 \%$ of passengers to proceed with their flight. The details of these behavioural characteristics are for obvious reasons confidential and they probably differ according to the social or political environment of the country from which the hijacking is being planned. Finally some or all of the passengers may be screened for weapons by magnetic devices (nearly all hijackers use firearms or knives) and if necessary by physical search. Further developments are likely in the field of weapon detection.

Even so it is a fact that hijackers do gain access to aircraft and disclose their intention only during the flight. At this stage the handling of the situation is firmly in the hands of the captain, whose efforts must be directed toward the safety of the passengers and preventing damage to the aircraft. Capture of the hijacker should not be a foremost objective.

Most hijackers are mentally unstable and should be treated as psychotics. Though they are unlikely to show any intellectual deterioration, their judgement is usually defective and their mood may fluctuate. The immediate task of the crew should be to reduce the anxiety of the hijacker. They should attempt to communicate with him, to find out where he wants to go, and to present an approach which appears to be helpful rather than obstructive. The crew should avoid any threat to his safety, and under these circumstances he may respond favourably. However, if his behaviour becomes bizarre an attempt to overcome him by force may be necessary. This is an extremely difficult situation to judge correctly and must be the ultimate responsibility of the captain.

Though in Western Europe hijacking has not become a serious threat, it is important that medical people should be prepared to provide what special skill they can offer, and students of behaviour should study this subject in an attempt to define the behavioural characteristics of individual hijackers. It may also be necessary to follow the example set in Canada $^{2}$ and provide crews with a sufficient understanding of disturbed behaviour to assist them in their safe handling of the situation.

\footnotetext{
${ }^{1}$ International Institute for Strategic Studies, A Strategic Survey 1972, 1973.

2 McArthur, W. J., Deanes, P. J., Carroll, J. R., Holliday, T., and Stokes, R. E., Aerospace Medicine, 1972, 43, 1118.
}

\section{Professional Advice after 1974}

Despite their initial reservations about the N.H.S., doctors have played an influential part in its running since 1948. As those primarily responsible for treating patients, their views have commanded attention on teaching and regional hospital boards, hospital management committees, and executive councils. Thus it is hardly surprising that the Government, as well as the profession, has spent much time studying and arguing how medical advice should be given locally in the reorganized N.H.S.

At present such advice comes broadly in three waysfrom doctors sitting on the various "executive" committees throughout the Service, from hospital medical committees (now evolving into Cogwheel) and their long established counterparts in general practice, the local medical committees, and, finally, from medical administrators in the hospital service. Since reorganization was first seriously mooted by Whitehall the B.M.A. has urged ${ }^{1}$ that whatever type of health authority eventually emerged from the shake-up its executive boards should contain at least one third of doctors among their membership. However, the present Government has been adamant that it wants such boards to be small, with their members chosen primarily for their abilities and not because they represent this or that group. ${ }^{2} 3$ Nevertheless, Sir Keith Joseph in the Bill now entering the Commons' Committee stage has guaranteed local authorities at least four members-appointed by them-on their area health authority. But beyond the Government acknowledgement that there will be some, doctors will not make up the 